\title{
The reaction in counter-action: How Meisner technique and Active Analysis complement each other.
}

\section{Philippa Strandberg-Long}

Biography:

Philippa is an actor trainer, director and researcher specialising in the Meisner technique. She teaches acting technique at several London conservatoires, coaches professional actors on and off set, and run workshops in the Meisner technique around the UK and Europe. Apart from this is also currently working on a $\mathrm{PhD}$ in Meisner technique and Cognition at the University of Kent.

\section{Keywords: Action, Counter-action, Reaction, Meisner technique, Active Analysis}

\begin{abstract}
:
This article is an investigation into the difference between reaction and counteraction. The question arose during my experience of Active Analysis at the Stanislavski Acting Laboratory in California Riverside University. In the Meisner technique the emphasis lies on instinctive reaction, whereas in Stanislavski's Active Analysis the action and counter-action are emphasised. Counter-action can be seen as the force working against the main action of the scene creating conflict. Having extensive knowledge of reaction, and experience of counter-action, it became important to understand the difference between the two concepts and the importance of both in actor training and application to text. Through research into ActionPerception theory, self-regulation and motivation, I attempt to dissect the fundamental discrepancies between the two principles. My findings show that reaction stems from impulse and instinct, whereas counter-action is rooted in motivation. When motivation and instinct are in conflict, self-regulation will attempt to supress the impulse and over-ride it with an alternative counter-action more suited to the overall motivation. As self-regulation is a limited resource, prolonged use will make this harder to control. Emotion control draws on the same limited resource as selfregulation. Suggesting that emotion regulation would be affected by a conflict in instinct and motivation. These conclusions have a strong impact on how emotions are manifested and produced in actors and warrant a re-evaluation of how actors reach
\end{abstract}


emotional connection to the given circumstance, as well as how emotion is viewed and engaged with in actor training in general.

During spring 2018 I travelled to The University of California for the international Stanislavski Acting Laboratory. My time at Riverside was spent working in a group consisting of theatre and acting practitioners from around the world, led by Stanislavski and Active Analysis expert Sharon-Marie Carnicke. Our quest, as a group, was to explore the difference between an improvisation ${ }^{1}$ and an improvisatory etude such as in Stanislavski's Active Analysis. The difference between these two aspects was an interesting concept and making this distinction would also be key for someone teaching and researching Meisner technique - a process that would also qualify as a series of improvisatory exercises, distinct from improvisations. Meisner himself opposed the use of improvisations that were based on dialogic word games, like the ones The Group Theatre had engaged in and which were later popularised by Keith Johnstone ${ }^{2}$ Meisner instead looked to create exercises that took the actors away from being the intellectual creators of a script and emphasised the listening and reacting to the partner instead.

\footnotetext{
...in the early days of the Group Theatre, the actors used to do what they called

“improvisations." .. . These were general verbalizations of what we thought was an approximation of our situation in the play. I came to the realization that this was all intellectual nonsense. A composer doesn't write down what he thinks would be effective; he works from the heart. I decided I wanted an exercise for actors where there is no intellectuality... to take away all the mental manipulation and get to where the impulses come from. ${ }^{3}$
}

Meisner believed that intellectuality created a sense of predictability that hindered real

\section{End notes:}

${ }^{1}$ Improvisations are often created spontaneously and without preparation, the actors become the creators of the script and are encouraged not to block each other's inputs. Improvisation practitioners like Keith Johnstone often work from game structure in order to further the creative dialogue between the actors (Gray, 2015:727). For this laboratory we defined an improvisation as an interaction between the actors where the lines are improvised and the structure might be as loose as a set of given circumstances, or in the case of our group stem solely from the inspiration of an object.

${ }^{2}$ Gray, Living Truthfully, 727.

${ }^{3}$ Meisner, Meisner on Acting, 36 
immediacy. ${ }^{4}$ He defined his improvisations as the actors co-creating a spontaneous, unpredictable, affective engagement in the moment. ${ }^{5}$ The most significant contrast to dialogical improvisations was that Meisner's did not seek to further the storyline in the way other improvisations did. ${ }^{6}$

Although Active Analysis uses paraphrasing, it is similar to Meisner technique in that it ultimately tries to "break down the wall between analysis and embodiment" 7 to find a less intellectual and more experiential way of doing this based on the interactions between the scene partners. ${ }^{8}$ Although my own experience of one particular exercise will be highlighted, this article will not be dissecting our exploration of Improvisation and Improvisatory exercises as such, but rather one particular aspect of Active Analysis and its relation to Meisner technique: Counter-action.

\section{What is counter-action and how does it differ from reaction?}

For Meisner acting was reacting, with a clear motivation to keep the actor spontaneous. ${ }^{9}$ In Meisner's process the students are encouraged to base their behaviour and actions on their instinctive reaction to the present moment. The driving force being their own, and the reading of their partner's, emotional impulses ${ }^{10}$. This kind of reaction is meant to be acted upon immediately and continuously throughout the interaction, allowing the impulses to bring about discoveries in the present moment, and not be suppressed. However, focusing on the notion of counter-action during the acting laboratory, raised questions about how an instinctive reaction differs from a counter-action.

At the heart of Stanislavski's improvisatory rehearsal tool, Active Analysis, lies the notion of action and counter-action. Stanislavski created this technique in the latter stages of his career, with the intention of fostering a freer and more reactive way to approach a script. His earlier work on Method of Physical Actions had made him question whether actions alone were sufficient, as well as whether the notion of counter-action is the crucial element in producing conflict and dynamic

\footnotetext{
${ }^{4}$ Gray, Living Truthfully, 727.

${ }^{5}$ Esper \& DiMarco, The Actor's Arts and Craft; Meisner, Meisner on Acting.

${ }^{6}$ Gray, Living Truthfully, 729.

${ }^{7}$ Carnicke, Stanislavski in Focus, 195.

8 ibid, 196; Merlin, Konstantin Stanislavski, 42.

${ }^{9}$ Zarrilli, The Psychophysical Actor, 17.

${ }^{10}$ Stinespring, Principles of Truthful Acting, 119.
} 
performances ${ }^{11}$. Counter-action can be seen as the force working against the main action of the scene, creating the contention, and struggle, which is ultimately integral to a dramatic situation.

Conflict [is] the clash produced when an impelling action meets a counteraction. Conflict may be direct (as in a fist fight) or oblique (as happens in the subtle plays of Anton Chekhov or in passive-aggressive encounters). ${ }^{12}$

Throughout our sessions with Carnicke it became clear that it was important to try to clarify the differences between an instinctive reaction and a counter-action. Since the ultimate application of actor training would be to take on a character through text this raises questions about the validity of training the initial reaction and its usefulness to the actor's scene work. To be able to answer this, it is necessary to explore how these approaches differ and the effect of one on the other. If a reaction is based on impulse, what would be the basis for a counter-action? Given that the action and counteraction in Active Analysis are based on the information from the text, the main focus in determining the counter-action would be the objective of the character in question. ${ }^{13}$ As the characters' needs and wants play out in corresponding actions, the main difference would seem to be the factor of the motivation. In an email interview $^{14}$, Carnicke agrees that, although she doesn't use the word objective specifically, counter-action and action is based on the given circumstances of the text - where we find what the characters want. The question then becomes: how does motivation affect instinctive reaction, and why train impulsivity if the application to text would require a counter-action, which might go against the initial feeling?

\section{Impulse versus motivation}

Impulses or urges can be seen as the immediate response to a situation, which people sometimes look to change or not act upon, whereas motivation would refer to a drive

\footnotetext{
${ }^{11}$ Carnicke, Stanislavski in Focus, 200.

12 ibid, 212.

${ }^{13}$ Merlin, Konstantin Stanislavski, 34

${ }^{14}$ Email interview with Sharon Carnicke 07/06/2018:

Q: My interpretation of it is that it is aiding something you want/need - rooted in the text?

A: Yes, Philippa, you are correct. If we were working on a text you would need to link your character's action or counteraction and also your choice of verb to the circumstances and facts of the text as written - what the character wants is usually encoded in the circumstances and facts. In the case of our lab, the action/counteraction and verb (when we had no text) were linked to what you want in terms of what your group set up as your circumstances. In early Stanislavsky, he actually used the word "want" to help actors see their scenes in active terms.
} 
to do something in order to serve a particular want - or the need to achieve a goal. ${ }^{15}$ Depending on the strength of our motivation, we might deem our impulsive reaction to be an unsuitable course of action and the way to change this would be through selfregulation.

Self-regulation refers to the capacity of [human beings] to override and alter their responses. It is the process by which people attempt to constrain unwanted urges in order to gain control of the incipient response. Regulation means change, especially change to bring behavior (or other states) into line with some standard such as an ideal or goal. ${ }^{16}$

There is not always a discrepancy between our instinct and objective. If a person's instinctive reaction would be in line with the motivation - for example if a building was on fire and the instinctive need was to get out - there would be no conflict between the reaction and the want and hence no need for self-regulation. It is only in the circumstances where the instinct and motivation are in conflict with each other that we adjust our responses. These conflicts can occur in a multitude of situations but are often linked to how we want to be perceived by others. We might view our impulsive response to not be socially acceptable or make us look less favourable in the eyes of others, so we regulate our behaviour accordingly. ${ }^{17}$ In Active Analysis we see these regulations in the form of actions and counter-actions: of course a counteraction could be based on a reaction, but it is the motivation of the character that ultimately drives it. So, how does Meisner's notion of training impulse apply to regulated actions and counter-actions?

Meisner and Stanislavski both based the development of their processes ${ }^{18}$ on the notion of Communion ${ }^{19}$ - Stanislavski's concept of communication and energy flow between actors during interaction. Active Analysis is similar to Meisner technique (and different to Method of Physical Actions) in terms of the attention being placed outwards, towards the partner, with the intention to enhance adaptability and presence in the actors. ${ }^{20}$ Although I acknowledge that my work with students on Meisner technique has enhanced listening, instinct and action selection, I was curious to find

\footnotetext{
${ }^{15}$ Baumeister \& Vohs, 2.

16 ibid

${ }^{17}$ Baumeister \& Vohs, Social and Personality Psychology, 5.

${ }^{18}$ In this case I refer mainly to the creation and development of Active Analysis.

${ }^{19}$ Merlin, Acting: The Basics, 183.

${ }^{20}$ Merlin, Konstantin Stanislavski, 42.
} 
out how it would affect situations in which we regulate our actions. In order to understand how action selection works I decided to build on my MA thesis research into Action-Perception theory and the idea that reactions stem from our perceived environment ${ }^{21}$.

\section{What is Action-Perception theory?}

In my MA research I discovered that Action-Perception is ultimately a survival mechanism used by humans and animals in order for them to navigate the environment. We perceive by interpreting the information we receive from our immediate surroundings, and act on this knowledge with the intention of putting ourselves in a more advantageous place. This creates an uninterrupted feedback-loop where the environmental stimuli influence the action we take, which in turn create new perceived stimuli, and so forth. Learning theorist Renate Caine explains how this daily process works:

As a result of acting, the organism gets feedback - new information from the world and from itself. That feedback provides the guidance about how the organism needs to act next time. [...] at its most basic, people observe, act and get feedback. ${ }^{22}$

Although this makes it sound as if there are three parts to this cognitive process observing, acting and getting feedback - later research suggests that action and perception follow each other instantaneously, and possibly simultaneously ${ }^{23}$. It was ecological psychologist James J. Gibson who coined the term Action-Perception in the 1960s. His research involved our interaction with the world visually and explored how that visual perception of our surroundings influences our physical actions. Some of Gibson's later work was focused on the notion of affordances; the way we afford certain values and judgments to what we see around us. In turn these judgment values are instrumental when deciding on an action. As my earlier research highlighted, Gibson argued that the perception and judgment are not two components separated in a linear process - but that they happen at the same time - hence our actions are instinctive reactions to visual stimuli. This was strongly contested by the philosophers

\footnotetext{
${ }^{21}$ The idea to look at Action-Perception theory in terms of the teaching of actioning in drama school was part of my MA Dissertation "Reaction in Action" 2012. Here the main exploration was how Meisner technique could be used to teach a foundation of actioning to drama school students.

${ }^{22}$ Caine, Natural Learning, 2.

${ }^{23}$ Decety, Current Opinion in Neurobiology; Giorelly \& Sinigaglia, Perception in Action.
} 
of mind and cognitive scientists at the time. ${ }^{24}$ The belief was that the mind separated action and perception and was the main decider on which action to take. The cycle, as it was seen at the time, was perception- cognition-action. However, the view of this has in latter years changed in favour of Gibson's model.

Over the last years several neurophysiological studies have offered us a very different description of brain architecture and functions. These researches have changed the standard view of sensory motor system and the motor system, shedding light on the mutual relationship between action and perception. ${ }^{25}$

This would indicate that training our actors' perceptions of their surroundings, and how we evaluate those perceptions in the moment, would be integral to our way of deciding on an action. The foundation of Meisner's work is focused on letting the instinctive reactions form the basis of our interaction, however a large part of the initial training emphasizes the placing of attention outside of ourselves onto our partner, in order to move away from the self-initiated action and allow the reaction to come from something outside of ourselves.

As the research into neuroscience and cognition has evolved, Action-Perception cycles have been reclaimed through the lens of social cognition ${ }^{26}$. Professor of psychology and neuroscientist Jean Decety, applies Action-Perception cycles to his work on social interaction. His work emphasises the intentions behind our actions and how this is influenced by other people's behaviour towards us. His view is in line with Gibson's discoveries as he describes the action-perception cycles and functionally intertwining action and cognition: "perception is a means to action and action is a means to perception". ${ }^{27}$

There is a difference between interacting with other humans and interacting with inanimate objects. The interaction between humans is more intricate and is referred to as natural action perception dynamic ${ }^{28}$. The dynamic, instant, continuous feedback loop between people happens in the present moment - simply put: we observe, we get

\footnotetext{
${ }^{24}$ Giorelli \& Sinigaglia, Perception in Action, 49

25 ibid

${ }^{26}$ Social cognition is the encoding, storage, retrieval, and processing, of information in the brain, which relates to members of the same species.

${ }^{27}$ Decety, Current Opinion in Neurobiology, 259.

${ }^{28}$ Full quote: "In human beings the process is more complex and we therefore call it the natural perception-action dynamic" (Caine, 2008: 2)
} 
feedback and we act. Referring to this, Decety states that the Action-Perception cycle creates the internal stimulus that leads to both our perception of someone else's action and our resulting reaction:

...these [internal] representations not only guide our own behaviour, but are also used to interpret the behaviour of others, because they are shared across individuals. ${ }^{29}$

Looking at this research, one can argue that focusing on training actors to stay present would be of importance. What the study of Action-Perception theory tells us is that these continuous feedback loops instigate our initial reaction and consequently determine our action, which happens in the moment. When the mind wanders from that present moment it enters a cognitive realm outside the Action-Perception cycle. Naturally the cycle does not stop during this time, but some internal representations formed will not be true to the moment - due to being imagined or remembered - and for actors the consequence is that some actions may not appear authentic to the audience as they cannot be adjusted according to the present interaction. Meisner technique teaches the importance of paying close attention to your scene partner's actions in order to keep you focused and open to spontaneous responses.

Meisner based his process on the idea that "What you do does not depend on you; it depends on the other fellow "30. This notion closely follows the science of the ActionPerception cycle - his exercises capitalising on the natural way humans interact. The repetition exercise trains the actors to base their actions on their impulsive reaction to their partner. The exercise also hones their skills in reading other people's behaviour whilst evaluating the reasons behind it. Thus, arguably, Meisner technique can be seen to train perception and by starting out in an environment free from other stimuli, we can learn to focus our attention on the dynamic force of the other actor. However, at this point we have to ask the question, what really lies behind our behaviour, and what we do to alter other people's behaviour?

Behaviour is adaptive, designed to allow the organism to prevent or accomplish something, while negotiating obstacles, i.e. it is action in the actor's sense. ${ }^{31}$

Blair is referring to the fact that the basis for our behaviour and actions is ultimately

\footnotetext{
${ }^{29}$ Decety, Current Opinion in Neurobiology, 262

${ }^{30}$ Meisner, Meisner on Acting, 36.

${ }^{31}$ Blair, The Actor, Image, and Action, 41.
} 
our objective, or our need to accomplish something. Now adding intention into the equation - the basis for counter-action - it would be of relevant to explore how the notion of goal-oriented behaviour would fit into the Action-Perception cycle.

\section{What about the counter-action?}

Patrick Haggard, from the Institute for Cognitive Neuroscience, differentiates between actions that are the result of an immediate reaction and actions that are driven by a clear intention. Besides the feeling of ownership with regard to initiating an intentional action, the brain processes engaged during these types of actions are set apart from those engaged during responsive actions ${ }^{32}$. Recognizing the difference in brain activity during intentional action and responsive action is vital in order to investigate my question fully - how reaction and counteraction differ and what part training each of them plays in actor training. Even though my main focus as a Meisner teacher has been to bring about spontaneity and impulsivity in the actors' work, one cannot dismiss the fact that human interaction is often bound by intentions and calculation and the neurological differences separating these types of action may be of significance for the teaching and directing of actors.

Further, Haggard flags up that neuroscientific studies into intentional behavior is a less travelled path than that of conscious perception. Nevertheless a consensus has been reached within the field that two types of action exist:

Human actions comprises of a spectrum extending from direct responses to immediate stimuli, to much longer ranging actions. The former often called 'automatic', whereas the latter may be called 'intentional'. ${ }^{33}$

For my research question it would be appropriate here to make the distinct link between automatic action and reaction, and intentional action and counter-action. However, it would seem that there is some contention here between the neurobiology and Action-Perception theory, given that automatic and intentional actions are seen as separate processes within the brain, although Action-Perception theory considers them as one. Gibson asserted that action was an integral part of perception; hence the information processing and the following decision-making would not be seen as separate processes. However, intentional action would appear to be following a more

\footnotetext{
${ }^{32}$ Haggard, Intentional Action, 695.

${ }^{33}$ Haggard, Conscious Intention and Motor Cognition, 291
} 
goal-oriented path, where final desired outcome would be part of the calculation.

Most desires need a string of actions in order to be achieved-even more so when involving the dynamic interactions of other humans. The action-sequence would start off with an intention - something that you want or need - the next actions can only be determined by continuously evaluating the response of the other people in the interaction. Will they help you achieve your goal? Will they stand in your way? What other obstacles occur whilst you are interacting? Will the goal take a long or short time to achieve? When does my action stop working? This is one way of the reaction and counter-action working together to create drama. The audience can most likely tell the desires of the actors, they know where each actor want to get to, but the journey there is explored in the moment, creating dynamic performances. Since these two actions do work together, are they both part of the Action Perception cycle? Neuroscientist Joaquin Fuster argues that intention is not just part of the cycle - but the Action-Perception cycle depends on it:

The Perception-Action cycle is the circular flow of information from the environment to sensory structures, to motor structures, back again to the environment, to sensory structures, and so on, during the processing of goal-directed behaviour. ${ }^{34}$

Fuster continues by adding that automatic actions - what I am referring to as a reactions- are situated in a different part of the brain cycle, to the more complex intentional actions, or counter-actions. However, both types of actions are connected by long fibers in the brain, making them equivalent in the executive rank and meaning that they are of equal importance during action selection ${ }^{35}$.

\section{Reaction + Counter-action $=$ Affect?}

Looking at this information from the perspective of Meisner technique and Active Analysis, I can see the importance of both reaction and counter-action within an

The set up of our improvisation etude:

Character 1 Action: To get character 2 to admit she was raped by their boss Tactic/Verb: To push/probe

Character 2 Counter-action: To get character 1 to drop the subject Tactic/Verb: To make light of 
actor's approach to the script. Furthermore, during the workshops with Carnicke I had an experience, which made me question the notion of affect and how emotion can be generated through conflict of motivation and impulse. During the second stage of our improvisational laboratory ${ }^{36}$ we had put our improvisation into the Active Analysis structure, which consisted of an action and a counteraction as well as a verb or tactic to play throughout the scene. The scene concerned a sensitive and highly emotional subject, something my character had experienced. I considered whether I would be required to engage in any kind of emotional preparation in order for me to access those kinds of emotions, or even connect to the stakes of this situation, but for the sake of the laboratory I decided to rely wholly on the outlined structure and process.

During the etude, my inner reaction to Character 1's action was completely different to my chosen tactic, which in turn created a strong conflict inside me. The more she pushed me to tell her the harder it became to make light of the situation. This struggle in turn created a strong emotional connection to the situation and at one point I felt physical pain in my body due to this inner turmoil and how difficult Character 1 made it for me to maintain this facade. There was a strong sense of self-awareness in this scene which was not hindering me as an actor, if anything it aided the situation. I was aware of everything I felt, as if I was really in this situation rather than as an actor playing a part. Self-consciousness became character consciousness, as I felt selfconscious as the person in this situation being watched and judged within the given circumstances - not by an audience. Character consciousness was a term used by both Stanislavski and Chekhov and referred to what happens when our imagination takes us from empathy or compassion to actually experiencing the feelings of our character due to the predicament of the situation. Chekhov referred to this as "a third I" - where we think, feel and pursue the same things as the character. ${ }^{37}$ In my experience at Riverside I felt extremely self-aware of my own behaviour, however it fully related to the circumstance and not to the fact that I was being watched. At no point did my fear, panic, sadness or awkwardness relate to my performance, but only to how my partner

\footnotetext{
${ }^{36}$ The first stage of the laboratory consisted of free improvisation stimulated from a chosen object. In the second stage we took the situation the first improvisation generated and structured it into characters with either Action or Counter-action and set verbs/tactics.

${ }^{37}$ Gillett, Acting Stanislavski, 123.
} 
was observing and behaving towards me. My feelings came out of the three-way struggle between my impulse, my motivation and my partner's action.

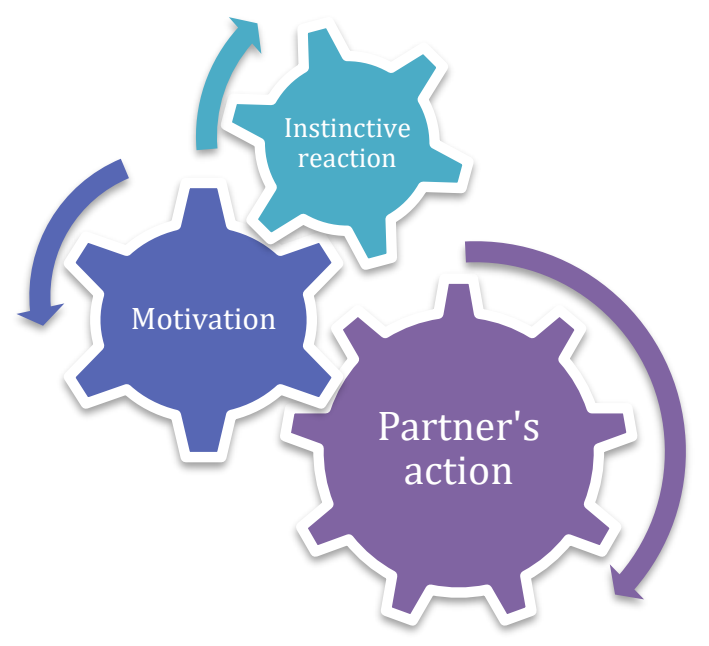

(Fig 1)

When asking Carnicke about her thoughts in regard to this she told me that in his later work Stanislavski never asked actors to work on specific emotions. He increasingly deemed emotion to be a sixth sense that would appear as a result of what we do. She added that Active Analysis presumes that if you are fully committed to a verb (provided it is well chosen in terms of the given circumstances and facts) emotional connection will follow - as had happened in our etude. ${ }^{38}$ Meisner also had thoughts along these lines when he stated that the motivation behind your actions should be the source of your concentration, which would generate the emotions by itself. ${ }^{39}$ This was clearly demonstrated to me in this exercise as emotions in turn create behaviour, which we observe in our partners and ourselves and evaluate from the perspective of our desired outcome. My experience reflected the integral connection between reaction and counteraction and in what manner they are strongly linked to affect.

Behaviour is the outcome of an internal struggle among many mental modules, and it is played

\footnotetext{
${ }^{38}$ Email interview with Carnicke 07/06/2018:

Q: The other question was regarding my experience of the verb working against each other so strongly that it caused an emotional connection in me when the obstacle was too great to play the verb: all I was looking for her was a comment from you on that etude, if you had any thoughts on what we experienced there.

A: Yes, the discovery that you made and what i said in our session was this: in his later years, Stanislavsky never asked actors to work on specific emotions. He saw emotion (like our ability to see or touch) as a sixth sense that comes naturally as a result of what we do. Active Analysis presumes that if you commit fully to your verb (provided that the verb is well chose in terms of the scene's circumstances and facts), emotion will result naturally (As it did for you in your etude)!
}

${ }^{39}$ Meisner, Meisner on Acting, 39. 
out on the chessboard of opportunities and constraints defined by other people's behaviour. ${ }^{40}$

What I experienced as 'character consciousness' related to the interaction between my partner and me coupled with how well I was doing in achieving my goal. This created a feedback loop influencing my behaviour and decisions and consequently generating emotions. I suggest that this is different to an actor experiencing self-consciousness if the changes in behaviour are the result of the motivation and the present communication that are firmly rooted in the imaginary circumstances.

At this point I return to the concept of self-regulation, as it also effects emotion. As stated earlier, when our instinctive reaction goes against what we believe to be the best action to achieve our goal, or the standard we have set for ourselves, we deploy self-regulation. ${ }^{41}$ Self-regulation needs some form of monitoring from the self in order to be initiated; hence the feedback-loop brings about a sense of self-awareness that is key to the interaction. ${ }^{42}$ As self-regulation refers to our ability to control our urges rather than acting on them, ${ }^{43}$ motivation plays a crucial part in deciding whether we achieve this or not. The stronger the motivation to achieve something, the harder the person will work to over-ride instinctive responses that would counteract that goal. This also relates to what is at stake, as the higher the stakes of the situation the more effort we devote to overcoming the obstacles. If the instinctive response however is very strong there will be a struggle between urges and impulses, which could lead to a decreased level of self-control. Self-control draws on a limited resource pool encompassing a wide variety of executive functions (attention, inhibition, working memory $\left.{ }^{44}\right)$. As this is a limited capacity the more it is being used the more it will be depleted. ${ }^{45}$ When this resource becomes depleted it is called 'ego depletion' and will affect our ability to change our behaviour. ${ }^{46}$

An interesting point here is that this depletion also affects our emotion-regulation ability. As humans we have a primary initial emotional response, which is followed

\footnotetext{
${ }^{40}$ Pinker, How The Mind Works, 42

${ }^{41}$ Baumeister \& Vohs, Social and Personality Psychology, 3

${ }^{42}$ There is always a feedback loop present in our interactions, however if there is not strong motivation the feedback revolves around the experience itself and it is evaluated from the perspective of past experiences and whether we want to change it or keep it the same (Csikszentmihalyi \& Nakamura, 2012:108-109)

${ }^{43}$ Baumeister \& Vohs, Social and Personality Psychology, 2

${ }^{44}$ Diamond, Executive Functions, 136.

${ }^{45}$ Muraven \& Baumeister, Psychological Bulletin, 248.

${ }^{46}$ Baumeister \& Vohs, Social and Personality Psychology, 4.
} 
by a secondary emotional response driven by emotion-regulation. ${ }^{47}$ Generally, the emotions regulated would be the less desirable ones like anxiety, anger, sadness or jealousy, which in turn would be more likely to occur in higher stakes situations. Social psychologists Gailliot, Zell and Baumeister have tested and confirmed the hypothesis that those involved in situations that require the use of self-regulation do find it harder to subsequently regulate their emotions. Their findings were based on a study in which participants were required to use self-control to engage in focused attention, change their writing style or over-ride a habit. The participants were then presented with situations that would normally induce emotions such as anxiety, sadness or jealousy. The results showed that, compared to those that had not been involved in self-regulating activities, participants that had, felt these emotions to a greater extent. ${ }^{48}$ Whilst those that had exercised self-control felt the emotions in a stronger way, further studies also suggest that emotions that are being regulated or worked against - using self-control to change how we are being perceived - will increase in strength as well as being harder to manage the longer the situation progresses. These emotions are also known to transmute into different kinds of emotions due to the suppression of them. ${ }^{49}$

When discrepancies between feelings and feeling rules exist, the discrepancy generates a new kind of negative emotional arousal, above and beyond the emotions initially experienced. Thus, a person who feels sad in a situation demanding the expression of happiness may also become angry at having to appear happy, thus racketing up the emotional intensity. ${ }^{50}$

\footnotetext{
${ }^{47}$ Koole, Cognition and Emotion, 22

${ }^{48}$ Gailliot, Zell \& Baumeister, Open Access, 1.

${ }^{49}$ Turner \& Stets, Annual Revue Sociological, 31

50 ibid, 27.
}

\section{Bibliography}

Alfreds, M. (2007) Different Every Night. Nick Hern Books.

Baumeister, R. \& Vohs, K. (2007) Self-Regulation, Ego Depletion, and Motivation. Social and Personality Psychology Compass Vol.1 , p.115-128

Blair, R. (2007) The Actor, Image, and Action: Acting and Cognitive Neuroscience. Routledge. 
Caine, R. (2008) Natural Learning: The Basis for Raising and Sustaining High Standards of Real World Performance, Position paper for The Natural Learning Institute.

Carnicke, S. (2008) Stanislavski in Focus: An Acting Master for the Twenty-First Century, Taylor and Francis.

Csikszentmihalyi, M \& Nakamura, J. (2012) Emerging Goals and the Self-Regulation of Behavior in R. Wyer's Perspectives on Behavioural Self-regulation, Psychology Press.

Damasio, A .(2000) The Feeling Of What Happens: Body, Emotion and the Making of Consciousness. Vintage.

Decety, J. (2004) Motor Cognition: a New Paradigm to Study Self-Other Interactions, Current Opinion in Neurobiology, Vol 14, p.259-263

Diamond, A. (2013) Executive Functions, The Annual Review of Psychology, Vol. 64, p.136-168.

Durham, K. (2003) Acting on and off: Sanford Meisner reconsidered. Studies in Theatre \& Performance, Vol. 23 Issue 3, p.151-163

Esper, W. \& D. DiMarco (2009) Actor's Art and Craft: William Esper Teaches The Meisner Technique. Anchor Books.

Frith, C. (2007) Making Up the Mind: How the Brain Creates Our Mental World. Wiley-Blackwell.

Fuster, J. (2004) Upper Processing Stages of Perception-Action Cycle, Trends in Cognitive Science, p.143-145

Gailliot, M, Zell, A. \& Baumeister, R. (2014) Having Used Self-Control Reduces Emotion Regulation-Emotion Regulation as Relying on Interchangeably Used "Self-Control Energy". Open Access Library Journal, Vol 1, p.1-14

Giorelli, G. \& Sinigaglia, C. (2007) Perception in Action, ACTA Biomed Vol 78, p.49-57

Gillett, J. (2014) Acting Stanislavski: A Practical Guide to Stanislavski's Approach and Legacy. Bloomsbury Publishing.

Gray, A. (2015) Living Truthfully Under Imaginary Circumstances: Improvisation in Psychoanalysis, Psychoanalytic Dialogues, Vol 25, p.725-742

Haggard, P. (2005) Conscious Intention and Motor Cognition, Trends in Cognitive Science, Vol 9 , p.290-295:

Haggard, P. (2003) Intentional Action: Conscious Experience and Neural Prediction, Consciousness and Cognition, Vol 12, p. 695-707:sep:

Ingold, T., ed. (2000) The Perception of the Environment: Essays on Livelihood, Dwelling and Skill. Routledge.

Koole, S.L (2009) The Psychology of Emotion Regulation: An Integrative Review, Cognition and Emotion, Vol 23, p.4-41: 
This would explain the intense emotions I was experiencing during our Active Analysis exercise, where my instinctive reaction and primary emotions were being suppressed by my counter-action, whilst continuously working against an obstacle (my partner's action). This continuous three-way conflict, in a high stakes situation, would take a lot of effort to uphold and hence be very likely to cause ego-depletion and reduced self and emotional control ability.

\section{Conclusion}

In this article I have attempted to investigate the main differences between the reaction in Meisner technique and the counter-action in Active Analysis. Meisner technique is foremost an actor training process and Active Analysis a rehearsal tool, I

Meisner, S. \& Longwell, D. (1987) Meisner on Acting. Vintage Books.

Merlin, B. (2001) Beyond Stanislavsky. Nick Hern Books.s[:-p]

Merlin. B (2003) Konstantin Stanislavski. Routledge.

Merlin. B (2010) Acting: the Basics. Routledge.

Moseley, N. (2005) Acting and Reacting. Nick Hern Books.

Muraven, M. \& Baumeister, R. F. (2000) Self-regulation and depletion of limited resources: Does self-control resemble a muscle? Psychological Bulletin, Vol 126, p. 247-259.

Noe, A. (2006) Action in Perception. MIT Press.

Pinker, S. (1997) How The Mind Works. Penguin.

Rizzolatti, G. \& Sinigaglia, C. (2007) Mirrors in the Brain: How our minds share actions and emotions. OUP Oxford.

Stanislavski, K. (1980) An Actor Prepares. Methuen Drama.

Stinespring, L. (1999) Principles of Truthful Acting: A Theoretical Discourse on Sanford Meisner. PHD Dissertation in Fine Arts, Texas University.

Thomas, J. (2016) Stanislavski's Active Analysis. Methuen Drama.

Turner, J. \& Stets, J. Sociological theories of human emotions, Annual Revue Sociological. 2006. Vol 32, p. $25-52$

Vohs, K. \& Baumeister, R. (Eds.). (2010) Handbook of Self Regulation Volume 2. Guilford Press Zarrilli, P. (2008) The Psychophysical Actor at Work. Routledge. 
therefore wanted to understand how the two concepts work together on text and the validity of training impulse. Having had a particularly strong emotional connection to an Active Analysis etude I questioned whether this was due to the inner reaction and counter-action working together and resulting in emotion.

Since reaction is based on immediate instinct I turned to Action-Perception theory in order to explore how natural action selection occurs. Action-Perception theory suggests that actions are instantaneously decided on, based on our perception of our environment, which relates to Meisner's notion of acting on impulse. However, given that the counter-action is seemingly based on motivation, this suggests that we do not always follow our instinct if we believe that our goal can be better achieved in a different way. Following this idea, I discovered that within Action-Perception theory there is an acknowledgement of two types of action, automatic and intentional, intentional being more goal motivated and less impulsive. Interestingly, these two actions are still linked inside Action-Perception feedback cycles and impact on one another.

During my own encounter with Active Analysis at the acting laboratory at Riverside where both my partner's action and my inner reaction worked against my ability to perform my counter-action - I experienced the effect of this triangle of effort (see fig.1) and the emotional connection that it manifested. As my investigation continued I discovered that when we alter our impulsive reaction to another action - depending on motivation - we employ self-regulation, which is a limited resource. It uses the same resource as emotion-regulation, which is the way we regulate mainly negative feelings as they occur. The discovery that these two regulatory functions use the same resource, and can become depleted, gave me an idea of what had happened during that exercise. My emotion regulation resource had become depleted due to using it to alter my immediate reaction to fit my counter-action, resulting in a stronger manifestation of emotion and the subsequent inability to keep playing my counteraction.

In conclusion this research has shown the importance of training impulse in actors and how instinctive reaction works in conjunction with action on text, and more specifically Active Analysis. Moreover, I would posit that the idea of the actiontriangle - inner reaction - counter-action - partner's action - can present actors with 
an effective way of accessing emotions which are wholly based on the present, the given circumstances and attention to the partner. 